\title{
Child Protection in Canada and England: A Comparative Analysis
}

\author{
Gabriela Ivan ${ }^{1}$ \\ ${ }^{1}$ Faculty of Sociology and Social Work, Bucharest, Romania \\ Correspondence: Gabriela Ivan, Faculty of Sociology and Social Work, Bucharest, Romania. E-mail: \\ numauita201973@yahoo.ca
}

Received: October 3, 2020

Accepted: January 13, 2021

Online Published: January 18, 2021

doi:10.5539/jpl.v14n1p100

URL: https://doi.org/10.5539/jpl.v14n1p100

\begin{abstract}
At a time when the Canadian child welfare is at a crossroads and strives for a direction that leads to better outcomes and engagement with the families and service providers, placing the Canadian child's welfare in the international context of child protection is essential for improving the system and learning from others.

This phenomenological research endeavours to compare the child protection systems of Canada and England from the legislation perspective, with the focus on the definitions of child abuse and neglect, in order to identify some of their similarities and differences and capture some aspects of the child protection workers' experience with the legislation and with these definitions. Furthermore, this explorative paper examines the implication of the legislation and the definitions of child abuse and neglect on the day-to-day work of the child protection workers who have experience in working in both countries - Canada and England - and identifies some of the similarities and differences of the two child protection systems.

The child-protection system in Canada and England has undergone many changes over the years to ensure the safety and wellbeing of all children, but the direct implications of these changes on the child-protection workers and their day-to-day work is little known and understood. While in England the child protection legislation is consistent along the country, in Canada each province/territory has its own legislation in child protection, and therefore each of them has policy manuals, guides and protocols providing working definitions of abuse and criteria used in making determinations of abuse.

The legislation and policy in child protection act as essential tools in the interventions with the main focus to keep children safe. In order to ensure that the children have the right to live a life free from any form of maltreatment, most countries have developed their own child-protection system, which is highly influenced by the cultural and socio-economic context of that specific country, as well as by the needs of its various communities.
\end{abstract}

Keywords: child protection in Canada and in England, legislation, regulations, child abuse, maltreatment, child neglect

\section{Child Protection in Canada and England}

Canada and England's child-protection systems are well known for their "legal, bureaucratic, investigative and adversarial approach," where the intervention is placed on the child's individual rights and on the investigation of the risks implied (Hill et al., 2002).Although one would expect that out of these two countries England would be the one with the longest tradition in child protection, it appears that the basis of the current child-protection systems in England and Canada developed around the same time. In England, the legislative framework for the current child-protection system was established in 1989 under the Children Act., while in Canada it was established in 1984 under the name of The Child and Family Services Act. While England somehow followed a conservative approach and opposed resistance to interference into the private family life, Canada was more inspired by its neighbour in utilizing the intervention of the government as a tool that breaks insurmountable obstacles in order to ensure the protection of its children. Canada's child welfare continues to be known for having an approach that is focused on safety rather than the child and family welfare (Gilbert et al. 2009, Fallon et al., 2012), despite the fact that the differential and alternative response was introduced in some of the Canadian jurisdictions with the hope to shift the balance towards a child and family welfare approach.

The child protection system in Ontario has changed and evolved over the years and a number of child welfare reforms have taken place. Policy reforms initiated in 2005 by the Ontario Child Welfare Transformation Agenda introduced a strategic plan that allowed for a more flexible outcome-oriented service delivery model. (Ministry of 
Children and Youth Services). By introducing the new Child Protection Standards in 2016, along with the 2016 enhanced version of the 2005 Eligibility Spectrum, the child protection system strives to better serve the children in need. (Ontario Child Protection Standards, 2016).

In the last years Canada's child welfare has started to move towards a Best Practice approach that strives to improve policies and services by providing standards for planning and delivering services in order to obtain "better outcomes" (Kramer, 2001, p. 157). Evidence Base practice aims to become the foundation of the best practices and provide the best possible services based on evidence (Mullen, 2006). However, the development of evidencebased approaches is a complicated task due to a limited consensus about the objectives of child-protection services (Trocmé, 2003), as the child protection workers need to decide between an intervention that focuses just on the child or views the child within the family context, where family and community are important partners in ensuring the child's safety and wellbeing.

An important milestone in child protection across Canada was met in 2016 when the majority of provinces and territories, with the only exception of Quebec, ratified the Provincial/Territorial Protocol on Children and Families moving between provinces and territories. This protocol clearly defines the roles and responsibilities of each jurisdiction providing child welfare services to children and families moving between provinces and territories, therefore it better protects all children regardless of their residence. (Provincial/Territorial Protocol 2016).

A new recording system in Ontario, respectively the CPIN (Child Protection Information Network) started its way in Ontario in 2015, with the goal of full implementation across the province by 2020. At this time, all Children's Aid Societies across Ontario, with the exception of Indigenous child protection agencies, adhered to CPIN. This new system enables the Children's Aid Societies across Ontario to securely share current and historical child protection information, and better manage case files and finances.

Do the recent changes along with the new recording system bring Canada closer to the progressive child welfare systems implemented by international leaders or more changes are required for a complete transformation of the child protection system in order to enable the child protection workers to better protect the children at risk?

\section{Conceptual Issues in Child Protection in Canada}

In Canada, the differences in the child protection systems along its provinces and territories impede the process of collecting data regarding child maltreatment. As such, the amplitude of the phenomenon of child maltreated across the country and the need of services to address it cannot be accurately reflected by the child welfare policies in a timely fashion. These differences are rooted in the historical context that has generated from the legislative systems governing Canada's jurisdictions. Moreover, the provincial funding scheme is reflected in the respective laws and regulations in child protection, as each jurisdiction wishes to respond to the communities that they serve.

While in England data collection regarding child maltreatment is conducted on a yearly basis (Department for Education, 2019), in Canada, because of the differences among the child protection systems across the federation, the data is collected every five years (Fallon et al., 2013). Therefore, two legitimate questions that rise in Canada are: how accurate is the assessment for the need of services, and how soon are the services that respond to the contemporary needs of the children and families in need of protection implemented? Although the original research was completed in 2012, it was the year 2020 that was anticipated to bring significant improvements in Canada's child welfare system, based on the five-year data collection scheme.

\section{Methodology}

Phenomenology has been selected as a main research method for this study, since its intent is to discover the working experience of the child-protection workers in relation to the legislation, the operational definitions of child maltreatment and its meaning. This qualitative study uses the hermeneutic phenomenology of Van Manen (1997), which has been identified as the best suited method for this study because professional child-welfare practice is enmeshed in people's life experience. The phenomenological inquiry proposed by Van Manner (1997) has been construed as a language that communicates the professional's experience in the child-protection field which offers "first-degree knowledge" (Scirneci, 2006). This qualitative approach focuses the attention on the individual's perspective and understanding of the impact of the experience, as it relates to them. The aim of the original research was to determine whether there is an association between the legislation, the operational definitions of child maltreatment in England and Canada and child protection worker's ability to protect, in the context of capturing the child-protection worker's experience with the legislation and the operational definitions of child maltreatment in their work. This study is part of a broader research completed on three countries, however the reference in this paper will be made strictly to Canada and England and to the experience of the child-protection workers with some aspects of the legislation, definitions of child abuse, neglect and the system in general, not to 
the in-depth analysis of all aspects of the legislation in the two countries that have been captured in the original research.

\subsection{Sampling}

In this research the purposive sampling (Patton, 2002) has been chosen to identify the primary participants and included people of interest and excluded those who did not suit the purpose. The researcher has selected individuals who had an expertise in working in England and Canada. Thus, all participants were child-protection workers with extensive experience in the field, and were active ongoing workers between 1998 and 2012. The snowball sampling (Patton, 2002) was used in the recruitment process, where participants were asked to recommend other prospective participants who met the criteria. The first six participants were selected based on networking, as the researcher is also a professional who works in the child-protection field. However, because of the difficulties to find and engage participants from other countries who met the criteria for this research, the snowball sampling (Onwuegbuzie \& Leech, 2007) was used as a technique to recruit more participants that met the research criteria. Each interviewee was asked to recommend other participants that would be appropriate for the research and willing to participate in it. The selected sample of 9 child-protection workers was found to be representative for the spectrum of the population needed for the research. The participants in this study were actively involved in analyzing their investigated experience by being reflective of their own practice.

\subsection{Demographics}

Out of the 9 participants, 5 identified as female and 4 as male; 8 as white and 1 as black. Their ages ranged from 35 to 54 years old $(M=45.6)$, and the years of experience from 3 to $22(M=12.6)$. The participants in the study had working experience as child-protection workers in the countries that were object to this study, and were actively involved in analyzing their investigated experience by being reflective of their own practice. In Canada, the comparison was based on the experience of child-protection workers active in two Canadian provinces, namely Ontario and British Columbia.

\subsection{Ethics}

In order to ensure ethical research, based on Bailey's recommendations (1996), a specific informed consent was developed. This consent referred to the purpose of the research, the procedures of the research, the risk and benefits of the research, the voluntary nature of research participation and the procedures used to protect confidentiality (Arksey \& Knight, 1999). This consent form was explained to each subject at the beginning of every interview, and henceforward only the participants who agreed with this content were selected to participate in the study.

\subsection{Data Collection and Analysis}

This study followed a general inductive data-analysis format (coding, categorizing, and thematizing). The researcher looked at every statement that was relevant to the questions asked in the study and created meaningful units that were clustered together in phenomenology-based categories. The advantage of using phenomenology is that it is able to employ numerous methods of data collection, including direct observation, in-depth interviews, while the data can be analyzed by using a constant comparative method that allows a conceptualization of the experience and its dimensions. Since the researcher is an instrument of data collection, interpretation, and analysis (Creswell, 1998; Denzin \& Lincoln, 2005), the researcher has brought both personal and professional experience into the researching process.

The epistemological position undertaken in this study can be formulated as follows: a) data are formulated from the perspective of child professionals working in the child-welfare systems in England and Canada; b) because of a), the researcher engages with the participants in collecting data.

The semi-structured, open-ended and in-depth interviews were conducted with child-protection professionals working in child-protection agencies in England and Canada, in person and over the phone. The data collected though these interviews was captured on digital tape and transcribed verbatim (Enosh, Ben-Ari, \&Buchbinder, 2008). At times, probes were used to encourage participants to provide an in-depth description regarding their experience with the legislation and the child protection system in general.

The interview questions progressively focused on identifying the child professional's experience in the field and covered the following areas: the overall experience of the child-protection workers in the child-protection system(s), with the focus on the strengths and weaknesses of the system and legislation; the operational definitions of child maltreatment, their strengths and weaknesses, and how the child-protection workers experienced them in their work; and, lastly, the connection between the operational definitions of child maltreatment and the reporting system. However, this paper focuses just on the first two area. 
The purpose of conducting interviews for this research was to collect information about the child-protection workers' experience with the policies, protocols, and practices in place over time, and to assess the nature of the relationship between these and the day-to-day practice. As such, the information gathered in the interviews was primarily used for descriptive purposes, and thereby the researcher employed the story-telling approach to present the child-protection workers' enriched experiences. Also, a limited amount of analysis was carried out for making relevant comparisons. In the process of comparing the experience of the participants from Ontario and British Columbia two provinces representative for Canada with the experience of the participants from England, the interview data were not considered in isolation, but merged with the information collected from the literature review that was also incorporated into this comparative analysis. A coding system was used to compile relevant information, and a few categories and subcategories have thus emerged.

The results of the study were used as a reference in emphasizing some of the changes that occurred in the Canadian child welfare between the time when this study was completed and the present time.

\subsection{Limitations}

In Canada the comparison was based on the experience of child-protection workers active in Ontario and British Columbia, and thus their experience took into account the policy and practice in their own provinces, which are different from other provinces, as in Canada each province has its own legislation, policies, and protocols.

\section{Results and Discussions}

A number of common themes have been identified in the interviews obtained from the participants, namely: the current legislation in child protection, authority to intervene, perception of operational definitions of child maltreatment (physical abuse, neglect, emotional abuse, sexual abuse), changes of the operational definitions of child maltreatment overtime, reporting the child maltreatment, working in collaboration with collaterals, working in collaboration with families, documentation, and services. However, only a few of these themes will be addressed in this paper.

\subsection{The Legislation in Child Protection in England and Canada}

The legislation in child protection is intended to be a useful tool for the child-protection workers' intervention in protecting the children. Therefore, the way it is defined and structured has a crucial role and deep impact on enabling the intervention.

In Canada, the twelve jurisdictions within this country have each developed their own child-protection legislation and definitions of abuse. Consequently, each of them has policy manuals, guides and protocols providing working definitions of abuse that have the role of specifying criteria and procedures that are to be used when making determinations of child abuse. (Swift, 1997). Despite all these differences, the child-protection legislation that refers to the major principles of the intervention is comprised in one act that has slightly different names across Canada.

All participants in the research indicated that the Canadian child-protection legislation is well structured, with comprehensive and well-organized operational definitions of child maltreatment that cover a large majority of the situations that might constitute child maltreatment. One of the participants described her experience with the legislation as follows:

Canada is more clear-cut when it comes to protecting the children and the legislation is the same for everyone. If I compare the Canadian system with the English one, I can say that the Canadian system is more organized.... I found that in Canada the focus is on the child's rights and protection and the child-protection legislation is organized in one piece of legislation that focuses just on the child. In Canada the law is one for everyone and is protecting all the children.

In Canada, the legislation that refers to the child-protection and intervention is well defined and organized in the Child Protection Acts, versus that used in England, which is ambiguous since it has multiple pieces of legislation that have implications in child protection, such as: the Children Act 2002, United Nations Convention on the Rights of the Child 1989(UN, 1989) ratified by England in 1991, the Human Rights Act 1998 which incorporates the European Convention on Human Rights into UK law, the Children and Young Persons Act 2008, and the Borders, Citizenship and Immigration Act 2009 (Section 55)which places a duty on the UK Border Agency to safeguard and promote children's welfare.

Although it was reported that overall, the legislation in both countries is good, Canada's legislation, in comparison with that of England, was described as "more organized" as comprised in one piece of legislation, therefore "fully protecting all the children." 
In the recent years the implementation of Bill C-92 in Canada has brought significant changes for many Indigenous communities by empowering them to develop their own policies and laws that are based on their history, culture and circumstances. Along with the implementation of the United Nations Declaration on the Rights of Indigenous Peoples, the ratification of the United Nations Convention on the Rights of the Child has brought significant changes to the child-protection system that serves Indigenous children.

\subsection{Use of Authority to Intervene}

As indicated by all participants, in Canada a child-protection worker is invested with a high authority. According to the Child and Family Services Act Ontario 2017 (Section 83.4), if a child-protection worker believes that a child is in need of protection and the child's health or safety are at immediate risk, can bring the child to a place of safety immediately, without a warrant. Moreover, a child-protection worker acting under this Act may call for the assistance of a police officer (Section 86.4).

The only province in Canada where the authority is balanced differently at the court level is British Columbia. In British Columbia, under the Child, Family and Community Services Act a judicial case conference is mandatory in new apprehensions. The focus of the case conference is on the needs of the child, rather than the fault of the caregiver and the judges would make orders that the parties agree to, refer to community mediators, or make orders that move the case to a formal hearing. (Schmidt, 2001).

In England, a child-protection worker does not have the authority to remove a child from its family environment unless a warrant or court order is obtained first. A warrant is issued by the Court or a Justice of the Peace.

The participants reported that the authority of a child-protection worker in Canada is granted by the childprotection legislation that enables the workers to intervene in the families immediately, and remove the child from the family, if the child is found to be at immediate risk of harm. It was acknowledged by the participants in the interview that Canada's child-protection legislation that enables the workers to remove the children in an immediate risk situation is important, but the emphasis should be placed on working with the family towards the change. One child-protection worker who participated in the research described her experience in working in the child-protection systems as follows:

I felt that in Canada I had a lot of authority in intervening in the family. [...] In England, I do not have the same authority as in Canada. Even the language used is different: in England, they do not use the term "apprehend," and I was told that they do not apprehend children; they just take the children away, temporarily. In Canada, I was able to remove the child from the home if I considered that the child was at risk. In England, if I want to remove a child, I need to call the police. I feel that by having the police there, I somehow share the liability with them. I believe that in Canada a worker who has a number of years of experience would make the right decision when deciding to remove a child, but if you leave this power in the hands of an inexperienced worker, it can cause damages to the children and their families.

In Canada, when the child-protection workers intervene in the family, they are faced with the dilemma of which approach to take, namely, to protect the child or to preserve the family; in such an instance, one does find it difficult to intervene in the context that serves both purposes. Thus, it was reported that lately the child-protection system has tried to acknowledge both the importance of the family in the child's life and the significance of preserving the family while the worker intervenes; however, the change is not implemented as fast as people would like it to be. It is also difficult for some workers to move from a child-focused intervention to a family-focused one, with all the pressure and scrutiny they face from the system and the media, along with the liability that they have to carry. The child welfare workers are often criticized for failing to protect children and blamed for being too intrusive when a child is removed from the family (Leigh, 2014).

Court intervention should be the last resort in the attempt to address the child welfare issues (Hawkins, 2002) and efforts should be directed towards client engagement. In the adversarial process where the child-protection workers increasingly rely on the court intervention to provide them with the authority to address the child-protection concerns, supporting the parent-child relationship becomes secondary (Cameron \& Freymond, 2003).

The child-protection workers in England reported that they enjoy less prestige in comparison with other professionals involved in children's wellbeing, and that their limited authority makes it difficult for them to intervene and protect a child in need. They also reported being unable to remove a child from the family although the child is at immediate risk unless they have a court order or police assistance. Moreover, the police have the possibility to remove a child from home up to 72 hours without a court order. On occasions the process to remove a child from home can be lengthy, so the child's life is in jeopardy until removed from the abusive environment by the police or judge. 
One of the participants recalled her experience in working in the child-protection field in England:

I was shocked when I started to work in England. I was denied access to the child's residence and met a high number of resistant parents who were very much aware of the rights given to them by the law.

The participants reported that even the language used in child protection is different. As it has already been mentioned, in England the term "apprehend" is not used, as it was found to have a negative connotation. Subsequently, the term "take the child away temporarily" is used instead. The ad litteram meaning of "apprehension" is "to take someone into custody and arrest by legal warrant or authority" (Merriam-Webster Collegiate Dictionary, 2011). Since this research was completed, Ontario has introduced significant changes to the language used in child protection, and some of the terminology allies with the one used in England. Likewise, the term "apprehend" is no longer used, having been substituted with "bring a child to a place of safety." Similarly, the term "crown wardship" has been replaced with "extended society care," while terms like "abandon" and "runaway" are no longer in use (Ontario Child Welfare Eligibility Spectrum, 2016). Although these changes are welcomed, there are still no significant changes in balancing the authority the workers are invested with.

An interviewee who works as a child-protection worker for a number of years in Canada advised that the child protection legislation that enables workers to remove the children in an immediate risk situation is important, but the emphasis should be placed in working with the family towards the change and the workers need to acknowledge that there is always a risk when you leave the child in the family, as you cannot fully control that environment but building on strengths can bring positive changes.

Compared with England, Canada has legislation which enables the child-protection worker to remove the children in immediate risk. Removing a child in immediate risk consists of removing the child from the family environment immediately if the child is found in imminent risk of harm. Though intrusive, this legislation can save lives.

\subsection{Perception of Operational Definitions of Child Maltreatment}

The operational definition of child maltreatment is the definition that appears in the child-protection legislation. An operational definition, which is also called functional definition, defines a specific process or validation test that is used to determine its presence and quantity (Adanza, 2006). The operational definitions of child maltreatment are of great importance to practice, as they provide a framework that ensures consistency in the intervention.

In Canada, there is no consensus on definitions of child maltreatment across the country. Although several jurisdictions have taken steps to set some criteria for defining abuse and neglect, the establishment of a completely standardized definition is constrained by the fact that, in practice, judgments about child maltreatment are shaped by a variety of complex factors.

It was reported that England has clear and comprehensive definitions of physical child abuse, physical neglect, failure to thrive, and emotional abuse that provide a solid framework for the practitioners in the child-welfare field. According to the participants in the study, the current operational definitions of child maltreatment in Canada and England are clear. However, the operational definitions used in Canada have been found to be more comprehensive.

The participants found the operational definitions of child maltreatment to be extremely important in their practice. They described the operational definitions of child maltreatment to be "essential for work," and "guide and framework" for practice.

A participant described her experience with the operational definitions as follows:

I believe that the operational definitions are extremely important as well as the overall legislation. For me, a child with a mark is a clear case of abuse; however, I noticed that some of my coworkers, who were lacking in socialwork training, needed a clear, black-and-white guide for the signs of abuse. These helped them through their practice to ensure the safety of the children.

It was reported that the operational definitions of child maltreatment provide a framework that ensures consistency in the intervention. The absence of the operational definition was described not just as leading to inconsistency in the intervention, but also as resulting in confusion and more intrusive actions, or no actions at all.

All interviewees considered that the operational definitions of maltreatment prevent them from misunderstanding and, subsequently, unjustified legal actions. Although the participants indicated that the definitions of child maltreatment are important and used as guides in their practice, they indicated that these definitions do not exclude their professional judgment, which is key in helping them to make a good assessment, and come as complementary. The operational definitions were described as "one piece of the puzzle," as a base point for the intervention.

Most of the participants in the study indicated that the most difficult type of maltreatment to intervene in is neglect, 
as most often poverty and neglect are intersecting each other (Daniel, 2005; Horwath, 2007). In Canada, neglect is one of the most common reasons for referral to child welfare agencies and the second largest category of substantiated maltreatment (Trocmé et al., 2005), while in England is the largest single category of harm on childprotection registers (Department for Education, 2010). In Canada, the definition of neglect refers to parents' failure or pattern to adequately care for, provide, supervise or protect the child and it does not make reference to the family's available resources. (Ontario Child Protection Standards, 2016).

Canada has a duty-to-report legislation and different protocols intended to ensure the close working relationship with the professionals involved with the children and their family. However, the responsibility to ensure the child's safety and wellbeing stays with the child-protection agencies. The results of the research show a strong connection between the operational definitions of child maltreatment and reporting the maltreatment, as these definitions help other professionals or non-professionals to recognize, and therefore to report, the child maltreatment.

\subsection{Working in Collaboration with the Families}

In the Canadian provinces of Ontario and British Columbia, the child-protection system introduced new reforms regarding the intervention in the family. These changes were intended to bring significant transformation of the system and to adopt a collaborative and holistic service approach with the ultimate goal to strengthen families and keep children safe.

The participants in the research reported that although in Canada the child-protection legislation invests the workers with the power to remove a child from home if the child is considered to be at immediate risk, and this tool could save the child's life as provides immediate intervention, nevertheless this power left in the hands of an inexperienced child-protection worker could lead to the situation where the child would be removed from home unnecessarily.

In England, the actual legislation supports every effort to preserve the child's home and family links, and contains the concept of "parental responsibility", which refers to the rights and responsibilities that a parent is invested by law over their child (Children Act 1989, Section 3). This perspective has some implications for the professionals working in child protection. For example, by comparing the two countries that constitute the object of this study, it was reported that England, because of its strong legislation, is taking the lead in working collaboratively with the parents/families, to ensure the safety and wellbeing of the children.

The child protection in Canada was reported to be based on the risk and focused mainly on the child, while in England the intervention is focused on the child within the family, and the best efforts are made to work collaboratively with the family to address the child-protection concerns.

All participants viewed working with the family as being crucial, and reported that removing the child immediately from the family is segregating the family unit, as the decision is based according to the participants in the research on "one window in time," without having all the information that enables one to come to the right decision.

The English child-protection system was described as working in partnership with the families/caregivers. As soon as a case advances to the child-protection level, a conference with all the collaterals involved and the family is summoned within (15) fifteen days. At the end of the conference, a Child Plan (CP) is developed. This plan is reviewed every three months, therefore, it is very clear for the family what is expected of them, whereas in Canada the child-protection workers mostly carry the burden of managing the cases by themselves.

A child-protection worker from England reported the following:

When a case comes to the child-protection level, then we immediately call a conference with all the collaterals involved and the family, and at the end of the conference we develop a CP plan that is reviewed every three months. It is also very clear for the family what is expected of them, whereas in Canada the worker carries the burden of managing the case, and the plans are made more for documentation purposes, and not for the families.

The participants related that within a seven-day period after the letter was sent to the collaterals to advise that the child was found in need a protection, the collaterals respond to the invitation for the initial child-protection conference (ICPE).

In Canada, the Plans of Care in numerous cases are made for the documentation and compliance purposes only, and not always in collaboration with the families and other collaterals, and most often the collaterals are not involved in developing these plans for various reasons. The service plans are the framework for establishing goals for each case (Child Welfare Gateway, 2012), therefore the English workers' approach, which involves the families, was found by the participants working in the system to be more efficient and leading to better outcomes.

In Canada, the child-protection system is highly focused on the child's best interest and on the risk involved. In 
the recent years, some changes have been implemented along with the legislation, thus emphasizing a differentiated response and an engagement with families through Family Group Conferencing, Family Centered Conferencing and Mediation. Introducing the Family Centered Conferencing in the child-protection practice provides "an approach to service practice that is based on respect, builds on family strengths, emphasizes safety, is culturally respectful and appropriate, and empowers families" (Wright \& Hiebert-Murphy, 2011, p. 445). However, despite all this changes more tools to shift the system towards working in partnership with the families by using a strengthbased method (Saleebey, 2002), along with a legislation that supports this, are yet to be developed.

The extended family and the community involvement have an essential role in looking after the children's wellbeing and has the responsibility to ensure that the children are protected from harm as the child protection is not an individual but rather a "collective concern" (Barter, 2001, p. 271).

It was reported that in Canada, working in segregation from the family resulted in a significant number of children being lost in the system. The participants acknowledged that without engaging the family and the community in the process no significant change would be registered or sustained.

\subsection{Working in Collaboration with the Collaterals}

Comparing with England, Canada is missing a clear legislative act that places the responsibility on all the professionals involved with the children and their families, so the liability and responsibility for safeguarding the children's wellbeing is not equally shared with the child-protection workers. As it takes a village to raise a child, it also takes a community to protect a child and support the family.

In England, The Children Act 2004 along with the Working Together to Safeguard the Children Act 2006, extended the legal duty on local authorities to safeguard and promote the welfare of children. Therefore, other agencies such as the police, health services and school are responsible for the safety and wellbeing of the children and must cooperate with the local authorities by law. Also, the Local Safeguarding Children's Boards (including health services, education, the police and other agencies) came to existence to enable the sharing the responsibility with the child-protection agency.

Typical of those working in Canada and England, a participant reported the following:

In Canada it is difficult to get information back from the collaterals or to have them involved. My working experience with the collaterals in Canada was frustrating. I had difficulties to reach these collaterals, and they were not returning my calls or responding to my correspondence. On a number of occasions, during the life of the case I would not be given the opportunity by these collaterals to have direct contact. In England I would just send a letter to the collateral and within 7 days I would get a response.

A child-protection worker can only act on what is known about the risk and wellbeing of the child, but can fail to protect if other professionals, though aware of a situation of abuse or neglect, are concealing the information for the fear of over-reporting or trying to preserve the relationship with the children's parents.

In England, on the other hand, the collaboration with other professionals was reported to be very good, and overall, the professionals were reported to be active players in the process of helping the child and the family and ensuring the safety and wellbeing of the child. In Canada, however, the partnership with the professionals involved with the family requires further development. The child-protection professionals who work in Canada indicated that many collaterals do not acknowledge their crucial role in protecting the children along with the child-protection agencies and fail to return calls/respond to the correspondence in order to provide updates regarding their work with the family.

The inter-professional collaboration and coordination of services have a crucial role in helping children and families in need (Goldman et al., 2003). The collaboration between professionals is leading service accessibility to users "if clients experience earlier interventions through a quicker response from service providers and the convenience of the service location" (Dowling, 2004, p. 313). Services collaboration that use formal agreements are proven to be more successful than informal agreements because they "systematically address matters such as voice, equity shares, and dispute resolution provisions that contribute to partnership success" (Hepburn et al. 2004, p.48).

Legislation resembling the one that is currently operational in England could foster open and continued communication between the child-protection agencies and the other professionals in the community, and therefore involve the collaterals in the process of planning and exchanging information towards ensuring the safety and wellbeing of the children and their families. 


\subsection{Services}

It has been reported that in Canada the wait list for services that are helping the children and families in need of protection are extensive. Although in Canada there are a variety of services that respond to the children's diverse needs, the long waitlists make them hardly accessible for the families and children in need. Although the childprotection workers have some influence and, through advocacy for their clients, can somehow expedite the waitlists, the families are still unable to access the service immediately. In order to increase accessibility and reduce the wait time, a number of agencies implemented the walk-in-counselling model that usually consists of a singlesession therapy that helps clients cope with long wait lists (Hoyt et al, 2014). However, this counselling model is not as efficient as long-term counselling, and the clients who are not comfortable with the change in counselors would be reluctant to use this service.

Due to delays in accessing the appropriate services, the situation often deteriorates, and in some cases leads to removing the child from the family, as it becomes unsafe for the child to remain within the family environment. It has been reported that in less severe cases, because of the extensive wait time to access the services, the family is discouraged and loses motivation to access that service when it eventually becomes available. Therefore, after the crisis has passed and the family somehow stabilized, the case is closed, although little to no change has been registered. Most of these cases have been reported to return to the system.

A child-protection worker active in the system for a number of years described his experience with the services as follows:

Most of my clients have difficulties to access services due to the long waiting list. Also, there are a variety of services that could significantly change the life of my clients, but they are hardly accessible. Due to this wait, some of the families get discouraged and lose faith in these services. My workload becomes overwhelming as I need somehow to substitute these services until they kick in.

The child-protection workers from England reported having a positive experience in accessing the services for the families and children in need. It was reported that in England the child-protection, safety and wellbeing of the children is by mandate a responsibility of all the professionals who work with the children. All collaterals were reported to be involved with the family, including physicians, who equally participate in the development of the Child Plan. When a letter is sent out in England by the child protection services to the collaterals informing them of a child-protection inquiry, the collaterals have the obligation to respond. Furthermore, after the child has been found in need of protection, within 15 days a case conference takes place, a Child Plan (CP) is developed and the parents are given 4 to 8 weeks to address the issue and connect with the services. After the service providers receive the referral and are informed that the $\mathrm{CP}$ was made, the family is serviced in a timely fashion, most often in less than two weeks after the plan was formulated.

The interviewees from Canada and England reported difficulties in accessing such services as hair-strand tests and parenting assessments that are critical in planning and monitoring, due to the limited budgets and the costs involved (both services are exceedingly pricey). Consequently, they use alternative services, such as drug urine/blood screens or internal assessments, as they are low-cost or involve no cost at all. Nevertheless, they have been reported not to be as efficient, and not to hold the same validity as evidence in court.

In Canada, the absence of a yearly data collection due to the differences among the child protection systems across the federation and the five years data collection (Fallon et al, 2013) creates difficulties in determining the service need accurately. Services that are available immediately strengthen the family and bring significant change, and any delay in service not just increases the risk but also builds resistance in engagement.

The services available for families in Canada and England are diversified. However, in England they are accessible in a timely fashion, while in Canada there are extensive waitlists for these services.

\subsection{Documentation}

The risk-averse tendencies of child welfare organizations that steamed from the societal culture of blame have resulted in demands for extensive documentation (Whittaker 2011). Also, a well-documented intervention provides transparency and accountability, it takes away precious time that the child-protection worker could use to foster engagement and partnership with families and children while intervening and providing services. Therefore the "time spent on paperwork outstrips, by far, time spent working directly with families and children". (Swift \& Callahan, 2006).

Typical of those working in Canada and England, a participant reported the following: 
The documentation in both countries is a challenging task that takes away the time from direct work with the family.

If things are not documented it is considered that they did not happen.

The participants in the study advised that a model that involves an individual file for each child in need of protection serves better the children in needs as this approach ensures the best service, so every child will have an individualized plan.

The child-protection workers in Canada and England are dealing with high caseload and workload that have different layers of complexity. As identified in the literature review, the caseload issues paired with the child welfare inquires have a direct impact on the child protection's worker ability to implement the best practice model (Anderson \& Gobeil, 2002; Connor, 2003; Smith \& Donovan, 2003). The high accountability and legal procedures take away valuable time that the child-protection workers could spend working directly with the families and make the child- protection workers feel overwhelmed and discouraged (Cameron et al, 2001; Regehr et al, 2000). Moreover, the workers need to juggle between meeting the double standards that are implemented, firstly by the ministry, and secondly by each child welfare agency.

\section{Conclusions}

By exploring the lived experience of the child-protection workers with the child-protection system in Canada and England, this study is hoping to inform the decision and policy makers. As evidenced by the outcome of this research, several strategies used by the child-welfare system in England could be implemented in Canada, to provide more comprehensive models that could overall improve the child-protection system and service delivery. These strategies steamed from the direct work experience of the child-protection workers, who exercise their duty to protect the children within the boundaries provided by the child-protection legislation and policies existent in Canada and England.

Compared with England, Canada is missing a clear legislative act that places the responsibility on all professionals involved with the children and their families, and shares the liability and responsibility for safeguarding the children's wellbeing with the child-protection agencies. This legislation could foster open and continued communication between the child-protection agencies and the other professionals in the community, and therefore involve the collaterals in the process of planning and exchanging information towards ensuring the safety and wellbeing of the children and their families. Although the child-protection agencies in Canada have a number of working protocols with the police, schools, shelters, etc., these protocols are mainly referring to reporting the maltreatment and work collaboration, but are insufficient to share the responsibility of protecting the children with the child-welfare agencies. In order to implement differential response models, a strong partnership between the child-protection agencies and the community agencies is imperative and the responsibility and liability need to be equally shared with the service providers (Waldfogel, 2001).

Mandatory meetings as in England - within 15 days after the case was opened to protection - that involve all collaterals and significant others in the child's life, along with regular follow-up review meetings every 3 months to monitor the family progress, would build bridges of successful partnerships with the collaterals involved, as well as with the families of children in need of protection, and therefore would lead to positive outcomes.

Canada needs to improve its service delivery that supports the children and families in need, therefore diverse and readily available services are required in order to bring significant changes to the current child-protection system. Moreover, the child-protection system has to resist to embracing the model that prescribes single solutions (Cameron, \& Freymond, 2003).

A consistent legislation in child welfare along the country that enables yearly data collection would provide a clear picture of the services that are needed to tackle contemporaneous issues in child protection. Therefore, the services that address these issues along with the funding to support them, would increase. Moreover, this would lead to an increase in partnerships between child welfare agencies and service providers who are able to offer services immediately after the case is opened to protection. The services available for the children in need and their families must be accessible in a timely manner and have the flexibility to move into the family home if required by the circumstances.

Prevention work in child protection should be given the same consideration as to the protection work. Through education and support, the number of cases of child maltreatment could decrease considerably. Institutions such as schools, hospitals, social welfare, and early-year centres could mitigate the factors that may lead to child maltreatment. While England and the Scandinavian countries are champions in this area, Canada is logging behind. Overwhelmed by the great number caseloads and lack of available community services that are serving the family in need, the Canadian child-welfare workers are often powerless in bringing significant changes in the children's 
life, and the system will continue to work in segregation with the focus remaining just on serving the child, not the child within the family. As the prevention occurs on three levels (services that prevent child welfare issues from occurring, available services that target the identified risks, and services that are preventing the reoccurrence Goldman et al., 2003), in order to move from child protection to child welfare, therefore from protection to prevention, an allocation and reallocation of appropriate resources would be required, along with a complete reorganization of all the structures of the child-protection system (Hetherington, 2002). In Canada, investments in prevention are a necessity that would decrease the overall cost of child protection, provide appropriate resources for successful parenting, and strengthen parenting skills, thus significantly reducing child maltreatment (Bowlus et al, 2003).

By adopting the model known as "a file for each child" in need of protection, Canada will ensure best services, and thus each child will have an individualized plan that addresses their issues.

Continued investment in trainings focused on clinical intervention should be established. These trainings would enable the child-protection workers to intervene in the family therapeutically, and balance the intervention between a forensic and a therapeutic approach. A clinical approach would not just help to understand the family dynamics, but also the decision-making which involves "nothing more than a human judge evaluating available information and arriving at a decision" (Ruscio, 145). In the recent years, such agencies in Ontario as the Ontario Association of Social Workers (OASW) have become leaders in providing and delivering a number of trainings for the child welfare sector. However, unless the workers have allocated time to absorb the knowledge provided by the trainings, this will become one more task among the plethora of tasks that the workers need to perform in the short span of the day.

It seems to be a trend of having the child-protection worker less involved in creating and developing the policies in child protection. Swamped in their work of meeting standards, the child-protection workers have less and less time to reflect on the impact that the policies have on their work. The data that is necessary to design the policies should be collected directly from the professionals working in the field and the policies should be pre-tested before being fully implemented.

The child-protection systems are complex. Though striving to best meet the needs of protecting the children, they have their own flaws. The proposed strategies in this paper highlight several areas of improvement, in the hope of opening the door to the possibility of change.

\section{References}

Adanza, E. G. (2006). Research methods: Principles and applications. Manilla: Rex Books.

Anderson, M., \& Gobeil, S. (2002). Recruitment and retention in child welfare services: A survey of child welfare league of Canada member agencies. Centre of Excellence for Child Welfare. Retrieved April, 2011, from http://www.cecw-cepb.ca/DocsEng/Recruitment.pdf

Andersson, G. (2006). Child and family welfare in Sweden. In N. Freymond, \& G. Cameron (Eds.), Towards positive systems of child and family welfare: International comparisons of child protection, family service, and community caring systems (171-190). Toronto: University of Toronto Press. https://doi.org/10.3138/9781442682726-007

Apprehend. (2011). In Merriam-Webster.com. Retrieved December, 2011, from https://www.merriamwebster.com/dictionary/apprehend

Arksey, H., \& Knight, P. T. (1999). Interviewing for social scientists. London: SAGE Publications. https://doi.org/10.4135/9781849209335

Arnold-Baker, C. (2008). English Law. In A Companion to British history. Loncross: Denholm Press.

Bailey, C. A. (1996). A guide to field research. Thousand Oaks, CA: Pine Forge Press.

Barter, K. (2001). Building community: A conceptual framework for child protection. Child Abuse and Neglect, 10, pp. 262-278. https://doi.org/10.1002/car.696

Bowlus, A., McKenna, K., Day, T., \& Wright, D. (2003). The economic costs and consequences of child abuse in Canada. Report to the Law Commission of Canada. Retrieved May, 2011, from http://www.cecwcepb.ca/sites/default/files/publications/en/ReportEconomic_Cost_Child_AbuseEN.pdf

Cameron, G., \& Freymond, N. (2003). Canadian child welfare: System design dimensions and possibilities for innovation (Rep., pp. 1-48). Waterloo, ON: Wilfrid Laurier University, Partnerships for Children and Families Project. 
Cameron, G., \& Freymond, N. (2006). Understanding international comparisons of child protection, family service, and community caring systems of child and family welfare. In N. Freymond, \& G. Cameron (Eds.), Towards positive systems of child and family welfare: International comparisons of child protection, family service, and community caring systems (pp. 3-25). Toronto: University of Toronto Press. https://doi.org/10.3138/9781442682726

Cameron, G., Freymond, N., Cornfield, D., \& Palmer, S. (2001). Positive possibilities for child and family welfare: Options for expanding the Anglo-American child protection paradigm. Waterloo, ON: Partnerships for Children and Families Project Faculty of Social Work, Wilfrid Laurier University Press.

Chelcea, S. (2001) Metodologia cercetării sociologice. Metode cantitative si calitative. Bucharest: Editura Economică.

Child Act 1989, UK. Retrieved from Legislation UK. Retrieved September, 2011, from www.legislation.gov.uk

Child and Family Services Act 1984, c 55.Ontario: Annual Statutes: Vol. 1984, Article 57. Retrieved September, 2011, from https://digitalcommons.osgoode.yorku.ca/ontario_statutes/vol1984/iss1/57

Child and Family Services Act 1990, R. S. O. Chapter C11. Retrieved September, 2011, from

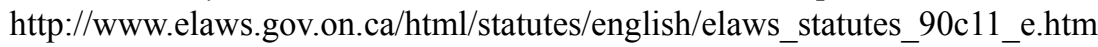

Child and Family Services Act 2017, SO 2017, c.14, Shed. 1(Section 83, 85, 86).

Child Welfare Information Gateway. (2012). Engaging families in case planning. Washington, DC: U.S. Department of Health and Human Services, Children's Bureau. Retrieved June, 2012, from https://www.childwelfare.gov/topics/systemwide/laws-policies/state/

Child Welfare Research Portal. (2011). Do child welfare systems differ from one Province and Territory to another? Retrieved September, 2011, from http://cwrp.ca/faqs\#Q7

Connor, A. (2003). The fatalities inquiry act report by provincial judge on inquest respecting the death of Sophia Lynne Schmidt.

Daniel, B. (2005). Introduction to issues for health and social care in neglect. In J. Taylor, \& B. Daniel (Eds.), Child neglect: Practice issues for health and social care (pp. 11-25). London: Jessica Kingsley.

Denzin, N. K., \& Lincoln, Y. S. (Eds.). (2005). London: SAGE Publications.

Department for Education and Skills. (2006). Statistics of education. Referrals, assessments and children and young people on the child protection registers, England: Year Ending 31, March 2005.

Department for Education. (2019). Characteristics of children in need: 2018 to 2019. Retrieved June, 2019, from https://www.gov.uk/government/statistics/characteristics-of-children-in-need-2018-to-2019

Department of Education and Skills. (2006). Working Together to Safeguard Children: A Guide to Inter-agency Working to Safeguard and Promote the Welfare of Children. London: Stationery Office.

Dowling, B., Powell, M., \& Glendinning, C. (2004). Conceptualizing successful partnerships. Health and Social Care in the Community, 12(4), 309-317. https://doi.org/10.1111/j.1365-2524.2004.00500.x

Enosh, G., Ben-Ari, A., \&Buchbinder, E. (2008). Sense of differentness in the construction of knowledge. Qualitative Inquiry, 14(3), 450-465. https://doi.org/10.1177/1077800407311962

Fallon, B. et al. (2012) Responding to chid maltreatment in Canada: Context for international comparison. Advances in Metal Health, 11(1), 76-96. https://doi.org/10.5172/jamh.2012.11.1.76

Fallon, B., Van Wert, M., Trocmé, N., MacLaurin, B., Sinha, V., Lefebvre, R., ... Rha, W. (n.d.). Ontario Incidence Study of Reported Child Abuse and Neglect-2013 (OIS-2013). Child Welfare Research Portal: Toronto, ON, Canada. Retrieved from www.cwrp.ca

Fuchs, D. (1995). Preserving and strengthening families and protecting children: Social network intervention, a balanced approach to the prevention of child maltreatment. In Hudson, J., \&Galaway, B. (Eds.), Child welfare in Canada: Research and policy implications (pp. 113-122). Toronto: Thompson Educational Publishing.

Gilbert, R., Kemp, A., Thoburn, J., Sidebotham, P., Radford, L. Glaser, D., \& Macmillan, H. L. (2009). Recognizing and responding to child maltreatment. The Lancet, 373(9658), 167-180. https://doi.org/10.1016/S0140-6736(08)61707-9

Goldman, J., Salus, M. K., Wolcott, D., \& Kennedy, K. Y. (2003). A coordinated response to child abuse and neglect: The foundation for practice. U.S. Department of Health and Human Services Administration for 
Children and Families Administration on Children, Youth and Families Children's Bureau Office on Child Abuse and Neglect. Washington, D.C. Retrieved September, 2011, from $\mathrm{http}: / / \mathrm{www} . c h i l d w e l f a r e . g o v / p u b s /$ usermanuals/foundation/foundation.pdf

Hawkins, K. (2002) Law as Last Resort: Prosecution Decision-Making in a Regulatory Agency. Oxford: Oxford University Press. https://doi.org/10.1093/acprof:oso/9780199243891.003.0013

Hepburn, N., LeSage, E., \& McMillan, M. (2004). Shared Service Arrangements: Determinants of Success. A Study of Economic Development and Recreation and Culture Shared Service Arrangements Among Municipalities of the Alberta Capital Region. Edmonton: Western Centre for Economic Research, University of Alberta.

Her Majesty's Government. (2004). Children Act 2004. London: Her Majesty's Stationery Office. Retrieved January, 2011, from http://www.legislation.gov.uk/ukpga/2004/31

Herbert, M. (2007). Creating conditions for good practice: A child welfare project. In Brown, I., Chaze. F., Fuchs, D., Lafrance, J., McKay, S., \& Thomas Prokop, S. (Eds.), Putting a Human Face on Child Welfare: Voices from the Prairie (pp. 223-250). Prairie Child Welfare Consortium / Centre of Excellence for Child Welfare.

Hetherington, R. (June 2002). Learning from difference: Comparing child welfare systems. Keynote Address at the Positive Systems of Child Welfare Conference, Waterloo, ON.

Hill, M., Stafford, A., \& Green Lister, P. (2002). International perspectives on child protection: Report of a seminar held on 20 March 2002: Part of the Scottish Executive Child Protection Review: Protecting Children Today and Tomorrow. Glasgow: Centre for the Study of the Child and Scottish Executive, University of Glasgow.

Horwath, J. (2007). Child neglect: Identification and assessment. New York: Palgrave MacMillan. https://doi.org/10.1007/978-0-230-20982-4

Houston, S., \& Griffiths, H. (2000). Reflections on risk in child protection: Is it time for a shift in paradigms? Child and Family Social Work, (5), 1-10. https://doi.org/10.1177/1473325011411010

Hoyt, M. F., \& Talmon, M. (Eds.). (2014). Capturing the moment: Single-session therapy and walk-in services. London: Crown House Publishing.

Iwaniec, D., Donaldson, T., \& Allweis, M. (2004) The plight of neglected children - social work and judicial decision making and management of neglect cases. Child and Family Law Quarterly, 16(4), 423-36.

Kramer, T. L., \& Glazer, W. N. (2001). Best practices: Our quest for excellence in behavioral health care. Psychiatric Services, 52, 157-159. https://doi.org/10.1176/appi.ps.52.2.157

Leigh, J. T. (2014). The process of professionalization: Exploring the identities of child protection social workers. Journal of Social Work, 14(6), 625-644. https://doi.org/10.1177/1468017313504380

Manen Van, M. (1997). Researching lived experience: Human science for an action sensitive pedagogy. London: Althouse Press.

Ministry of Children and Youth Services. (2010). Report on the 2010 Review of the Child and Family Services Act. Toronto, ON.

Ministry of Children and Youth Services. (2013). Formal customary care: A practice guide to principles, processes and best practices. Toronto, $\mathrm{ON}$.

Ministry of Children and Youth Services. (2016). Child protection standards in Ontario. Retrieved June, 2020, from www.children.gov.on.ca/.../childwelfare/protection-standards/index.aspx

Mullen, E. J., \& Streiner, D. L. (2006). The evidence for and against evidence-based practice. In A. R. Roberts, \& K. R. Yeager (Eds.), Foundations of Evidence-based Social Work Practice (pp. 22-34). New York: Oxford University Press.

Munro, E. (2005). Improving practice: Child protection as a systems problem. Children and Youth Services Review, 27(4), 375-391. https://doi.org/10.1016/j.childyouth.2004.11.006

Office of Children's Commissioner. (2010). Family perspectives on safeguarding and on relationships with children's services. London: Office of the Children's Commissioner.

Ontario Child Welfare Eligibility Spectrum. Toronto, ON. (2016). Retrieved May, 2020, from http://www.oacas.org/publications-and-newsroom/professional-resources/eligibility-spectrum

Onwuegbuzie, A. J., \& Leech, N. L. (2007). Sampling designs in qualitative research: Making the sampling process 
more public. The Qualitative Report, 12(2), 238-254, Retrieved June, 2011, from https://nsuworks.nova.edu/tqr/vol12/iss2/7

Padgett, D. (2008). Qualitative methods in social work research. London: SAGE Publications.

Patton, M. Q. (2002). Qualitative research and evaluation methods. London: SAGE Publications.

Provincial/Territorial protocol on children, youth and families moving between Provinces and Territories. (2016). Child Welfare Research Portal. Retrieved June, 2019, from www.cwrp.ca

Regehr, C., Leslie, B., Howe, P., \& Chan, S. (2000). Stressors in child welfare practice. Information for Practice, 1(2). Web-based journal.

Ruscio, J. (1998). Information integration in child welfare cases: An introduction to statistical decision-making. Child Maltreatment, 3(2), 143-156. https://doi.org/10.1177/1077559598003002008

Saleebey, D. (Ed.). (2009). The strengths perspective in social work practice. Boston: Allyn and Bacon Press.

Schmidt, D. E. (2001). The child, family and community services act British Columbia: Judicial case conferences. Materials prepared for the National Judicial Institute, Vancouver, B. C.

Scirneci, F. (2006). Indrumar de cercetarecalitativa in stiintele socio-umane, Bucharest.

Smith, B., \& Donovan, S. (2003). Child welfare practice in organizational and institutional context. Social Service Review, 77(4), 542-563. https://doi.org/10.1086/378328

Swift, K. J. (1997). Canada: Trends and issues in child welfare. In N. Gilbert (Ed.), Combatting child abuse: International perspectives and trends (pp. 38-71). Oxford \& New York: Oxford University Press.

Swift, K. J. (2011). Canadian child welfare: Child protection and the status quo. In N. Gilbert, N. Parton, \& M. Skivenes (Eds.), Child protection systems: International trends and orientations (pp. 36-59). Oxford \& New York: Oxford University Press. https://doi.org/10.1093/acprof:oso/9780199793358.003.0003

Swift, K., \& Callahan, M. (2006). Problems and Potential of Canadian Child Welfare. In Freymond N., \& Cameron, G. (Eds.), Towards positive systems of child and family welfare: International comparisons of child protection family service, and community caring systems. Toronto, $\mathrm{ON}$ : University of Toronto Press. https://doi.org/10.3138/9781442682726-005

Trocmé, N. (2003). The Importance of Process in Developing Outcome Measures. Keynote Address at the Canadian Symposium of Child and Family Services Outcomes: the State of Outcomes in Canada.

Trocmé, N. (2011). Canadian incidence study of reported child abuse and neglect, 2008: major findings. Ottawa: Public Health. Agency of Canada.

Trocmé, N. et al. (2005). Canadian incidence study of reported child abuse and neglect - 2003: Major findings: Minister of Public Works and Government Services, Canada. https://doi.org/10.1016/j.chiabu.2003.07.003

Waldfogel, J. (2001). The future of child protection: How to break the cycle of abuse and neglect. Cambridge: Harvard University Press.

Webber, E., \& Feinsilber, M. (1999). Merriam-Webster's dictionary of allusions. New York: Merriam-Webster. Inc.

Wharf, B. (2002). Community work approaches to child welfare. Peterborough, ON: Broadview Press.

Whittaker, A. (2011). Social defences and organisational culture in a local authority child-protection setting: Challenges for the Munro Review. Journal of Social Work Practice, 25(4), 481-495. https://doi.org/10.1080/02650533.2011.626654

Wright, A., \& Hiebert-Murphy, D. (2011). The application of family-centered practice in the child welfare context. In K. Kufeldt, \& B. McKenzie (Eds.), Child welfare: Connecting research, policy and practice (pp. 445-458, 2nd Ed.). Waterloo, ON: Wilfred Laurier University Press.

\section{Copyrights}

Copyright for this article is retained by the author(s), with first publication rights granted to the journal.

This is an open-access article distributed under the terms and conditions of the Creative Commons Attribution license (http://creativecommons.org/licenses/by/4.0/). 